\title{
Urgensi Keberadaan Bahasa Arab di SMA Untuk Deradikalisasi
}

\author{
Mufidul Abror dan An'im Fattach \\ Universitas Islam Lamongan, Indonesia \\ Email corresponding author: mufidulabror1986@gmail.com/an.imfattach@gmail.com
}

\begin{abstract}
ABSTRAK
Penelitian ini bertujuan untuk mengembangkan dan menghasilkan suatu alat atau metode untuk memecahkan suatu permasalahan dalam pendidikan yang menerapkan hasil penambahan materi deradikalisasi untuk mencegah radikalisme. Penelitian ini dilakukan karena maraknya teror dan kekerasan yang mengatasnamakan agama. Selama ini pemerintah hanya fokus pada penanggulangan pascateror seperti rehabilitasi teroris serta pelatihan bagi dosen dan pimpinan perguruan tinggi untuk mengantisipasi radikal dan terorisme. Sayangnya, tidak ada tindakan preventif untuk menghentikan radikalisme di kalangan anak muda seperti pelajar di sekolah menengah atas. Padahal, sasaran radikalisme lebih difokuskan pada kaum muda. Oleh karena itu, dengan menggunakan pendekatan desain penelitian, penelitian ini mencoba menerapkan materi deradikalisasi pada pembelajaran bahasa Arab di SMA. Hasil penelitian menunjukkan bahwa penerapan materi deradikalisasi dapat meningkatkan motivasi belajar bahasa Arab dan pemahaman Al-Qur'an siswa. Selain itu, penambahan kosakata deradikalisasi sangat dianjurkan dalam buku teks bahasa Arab untuk memberikan pencerahan kepada siswa tentang bahaya radikalisme.
\end{abstract}

Kata Kunci: Deradikalisasi, Agama, Bahasa Arab

\section{ABSTRACT}

The aim of this research is to develop and produce a tool or method in order to solve a problem ineducation that apply result of adding deradicalization material to prevent radicalism. This study is conducted due to rise of terror and violent in the name of religion. So far, the government has only focused on post-terror countermeasures such as rehabilitation for the terrorist as well as training for lecturers and university leaders to anticipate radicals and terrorism. Unfortunately, there is no preventive action to stop a radicalism among young people such as students in the senior high school. Even though, the target of radicalism is focused on the young people. Therefore, by using research design approach, this study try to apply deradicalization material on Arabic lesson in senior high school. The result show that the application of deradicalization materials can enhance the students' motivation in learning Arabic and understanding the Qur'an. Furthermore, the adding of deradicalization vocabularies ia highly recommended in Arabic textbooks in order to give an enlightenmentfor student about the danger of radicalism.

Keywords: Deradicalization, Religion, Arabic

\section{PENDAHULUAN}

Dengan temuan pelaku tindakan terorismeyang berusia remaja (15-19 tahun) adalah merupakan bukti bahwa radikalismeagama telah mengakar dan menjadikan usia remaja sebagai target penyebaranya tanpa terkecuali para pelajar SMA. Minimnya penguasaan dalam bahasa arab adalah problem dasar akan parsialnya pemahaman agama Islam sehingga menyebabkan pemahaman Islam yangcenderung legalistik dan ekslusif yang memicu tindakan radikalisme 
yang mengatasnamakan agama. Sebab dengan minimnya penguasaan bahasa arab akan berimbas pada kurangnya penguasaan pemahaman akan teks Al-Qur`an dan naskah-naskah klasik agama sebagailiteratur rujukan utama dalam mengkontekstualisasikan nilai-nilaiagama dalam kehidupan.

Dewasa ini, dalam menginterpretasi ayat- ayat al-Qur'an hususnya tentang jihad fii sabilillah amatlah beragam dan akhirnya melahirkan golongan Islam puritan dangolongan Islam yang moderat. Pada kalangan yang puritan dan fanatik jihad dimaknai secara tekstual, yaitu perang yang sesungguhnya dengan jiwa raga, harta benda sebagai ibadah tertinggi dengan jaminan surga. Hal ini berbeda dengan kalangan moderat yang memaknai jihad dengan kontekstual, yaitu sebagaiusaha sungguh-sungguh dalammengekang hawa nafsu manusiawi agartidak melakukan hal-hal yang dilarang agama, jihad juga dimaknai sebagai berjuang dalam mencari nafkah untuk keluarga, menuntut ilmu, dan makna lainnya. Dari pemaknaan jihad yang tekstual itulah yang melahirkan paham dantindakan yang radikal di kalangan masyarakat Islam begitupun dikalangan pelajar.

Pada usia remaja (15-19 tahun) Pesertadidik Sekolah Menengah Atas dari segi usia berada masa peralihan dari masa kehidupan anak-anak menuju masa kehidupan orang dewasa. karenanya para peserta didik SMA pada masa ini banyak melakukan berbagai aktivitas untuk menemukan jati dirinya (ego identity). Atau berada pada tahap kepercayaan sintetik konvensional. Pada tahapan ini perkembangan keagamaan peserta didikSMA dapat diarahkan dengan baik bilamereka mendapatkan pengetahuan dan pengalaman keagamaan secara baik dan benar. Di sisi lain perkembangan keagamaan peserta didik SMA akan menjadi buruk bila sebaliknya, apalagi jikamereka mendapatkan pengetahuan dari kelompok radikal dan hal itu tentu dapat membahayakannya, Itulah problem perkembangan keagamaan peserta didikSMA saat ini yang harus benar-benar diperhatikan oleh berbagai pihak, khususnya guru Pendidikan Agama Islam (PAI) dan bahasa arab di SMA.

Bahan ajar yang berupa buku sebagai sumber belajar harus menyajikan materi yang sesuai dengan garis besar pembelajaran yang termuat didalam kurikulum. Materi pembelajaran harus dikembangkan dengan pemahaman deradikalisasi dan juga berbasis media sosial sehingga memberikan nuansa baru didalam proses pembelajaran.

Dalam rangka membangun karakter yang baik dalam diri anak didik, lembagapendidikan atau setiap sekolah semestinya menerapkan semacam "budaya sekolah" dalam rangka membiasakan karakter baik yang akan dibentuk. Budaya sekolah dalam pembentukan karakter ini harus terus-menerus dibangun dan dilakukan oleh semua yang terlibat dalam proses pendidikan di sekolah. Lebih penting lagi dalam hal ini adalah agar para pendidik hendaknya dapat menjadi suri teladan dalam mengembangkan karakter tersebut.Sungguh, sebagus apapun karakter yang dibangun dalam lembaga pendidikan apabila tidak ada suri teladan dari pendidiknya, akan sulit dicapai karakter baik bagi peserta didik. Apalagi jika pendidikan karakter itu belum konsisten dilaksanakan oleh sekolah dan kurang dukungan serta motivasi dari warga sekolah maka pendidikan karakter masih jauh dari yang diharapkan. Maka dari itu peran sekolah sangat diharapka oleh masyarakat sebagai tempat penanaman karakter baik bagi peserta didik.

\section{METODE PENELITIAN}

Penelitian ini merupakan jenis penelitian disain (Design Research). Penelitian ini dilaksanakan dengan tujuan untuk mengembangkan dan menghasilkan sebuah produk sebagai suatu pemecahan masalah yang ada di dunia pendidikan. Produk yang akan dihasilkan dalam peneltian ini yaitu buku ajar pelajaran bahasa Arab. Penelitian ini menggunakan model pengembangan, dimana langkah- langkah yang dilakukan secara sistematis dalam proses perancangandan pengembangan buku ajar yang diwujudkan dalam bentuk narasi atau diagram. 
Penelitian ini menggunakan model pengembangan yang diadaptasi dari model yang dikembangkan oleh Plomp yang disebut sebagai model penelitianPlomp. Berdasarkan Plomp and Nieveen(2013: 30), ada tiga tahapan dalam penelitian pengembangan Model Plomp ini, yaitu fase analisis pendahuluan (PreliminaryResearch), fase pengembangan atau pembuatan prototype (Development or Prototyping Phase), dan fase penilaian (Assessment Phase). Dengantahapan sebagai berikut:

1. Evaluasi diri (Self-Evaluation), peneliti memeriksa atau mengevaluasisendiri prototipe 1 yang telah dirancang.

2. Penilaian Ahli (Expert Review), Pada tahapan ini, para ahli memberikan diminta mengevaluasi ataumemberikan penilaian dan saran-saranterhadap rancangan produk untuk menentukan kekurangan dan kelebihan, serta memperhatikanspesifikasi produk yang diharapkan yaitu berdasarkan aspek didaktik, aspek isi, aspek bahasa, dan aspek penyajian/ kegrafikan.

3. Evaluasi Perorangan (One-to-one Evaluation), tahapan ini dilaksanakan terhadap tiga orang peserta didik yangmemiliki kemampuan berbeda-beda (heterogen). Peserta didik diminta untuk memberikan komentar mengenai kepraktisan buku ajar bahasa arab yang dikembangkan.

4. Evaluasi Kelompok Kecil (Small Group Evaluation), tahapan ini dilaksanakan terhadap peserta didik yang memiliki kemampuan heterogen. Peserta didik belajar dengan menggunakan buku ajar bahasa arab. Peserta didik diminta untuk memberikan penilaian terhadap buku ajar bahasa arab yang sudah dikembangkan.

\section{PEMBAHASAN}

Dua entitas yakni, Budaya dan bahasa merupakan sepasang yang tidak dapat dipisahkan, bahasa dan kultur mempunyai hubungan yang signifikan. Hal itu mengingat posisi keduanya yang saling berkelindan baik secara mikro pun makro. Dalam konteks mikro, pikiran merupakan media komunikasi antara keduanya. Sementara dalam kerangka makro instrumennya merupakan kognisi sosisal. Sejalan dengan pendapat di atas, Nosowicz mengatakan bahwa budaya merupakan simbol akumulasi ragam ide dan aksioma individu dalam struktur sosial masyarakat yang pada gilirannya menciptakan kognisi kultural. Lazimnya hal itu secara aksiologisdapat teridentifikasi melalui ekspresi (bahasa) masyarakat yang ada di dalamnya ${ }^{1}$ Relasi antara bahasa dan budaya menjadi diskursus yang banyak mendapatkan atensiakademisi dalam pedagogi bahasa. Secara umum dialog mengarah pada posisi aspek budaya di dalamnya. Dalam perspektif Giles dan Powesland, pengajaran bahasa bersifat independen. Dengan kata lain bisamenafikan aspek budaya di dalamnya. Senada dengan hal tersebut, Kramsch menjelaskan bahwa pedagogi bahasa yang berfokus pada kompetensi komunikatif danperolehan keterampilan berbahasamempunyai perbedaan dengan pengajaran sastra yang berfokus pada analisis, interpretasi, dan terjemahan manuskrip dari bahasa satu ke bahasa lainnya. Dalam pengajaran bahasa, aspek terpenting adalahlinguistik, sementara aspek budayamenjadi identitas kelas sastra. Di sisi lain, banyak para ahli yang berpendapat bahwa budaya merupakan elemen penting dalam pengajaran bahasa asing. Tesis tersebut misalnya diajukan oleh Asosiasi Bahasa Modern Amerika.3 Lebih lanjut Eldin berpendapat bahwa kajian budaya menjadipenting dalam pengajaran bahasa karena berbagai peran sosio-kultural melekat secara inhern dalam diri pengguna bahasa. Oleh karenanya pemelajar bahasa perlu memperhatikan berbagai variabel yang berkaitan dengan budaya, misalnya: usia, status, jenis kelamin, dan latar pendidikan.Dalam perspektif Meier, variabel tersebut merupakan sesuatu yang sensitif yang dapat melahirkan multi-interpretasi sebagai konsekuensi logis dari distingsi kultural,sehingga berpotensi menjadi misskonsepsi. Sejumlah pandangan ahli diatas menjadi penegas bahwa pembelajaranbahasa asing tidak bisa 
menafikan aspek budaya penutur aslinya.

Bahasa asing sebagai objek pembelajaran juga menjadi atensipemerintah Indonesia sedari lama. Hal itu mengingat posisi strategis bahasa yang dijadikan media untuk membangun atau mengembangkan peradaban Nasional. Salah satu bahasa asing yang mendapatkanperhatian pemerintah adalah bahasa Arab. Secara historis bahasa Arab masuk beriringan dengan agama Islam di Indonesia. Oleh karenanya tidak mengherankan bila bahasa Arab di Indonesia identik dengan doktrin agama, bahkan sampai sejauh ini budaya masyarakat dalam mempelajari bahasa Arab masih diwarnai corak teologis-tradisi4 Kendati demikian, dampak globalisasi telah mereduksi sedikit demi sedikit corak tersebut dan menggantinya dengan motif komunikasi. Motif tersebut secara instrumental tidak terbatas pada pengetahuan tentang bahasa Arab, namun juga termasuk aspek pragmatik yang mempunyai relevansi dengan aspek budaya masyarakat Arab dan Indonesia.5 Konsekuensi logisnya kajian terhadap aspek interkultural dibutuhkan dalam pengajaran bahasa Arab untuk meningkatkan efektifitas dan efesiensi dalam proses di dalamnya. Afirmasi dari tesis di atas telah dikemukakan oleh beberapa akademisi, misalnya (Omar; 20167, Lewicka; 20168, Aflisia; 20199). Sejumlah kajian dari para akademisi tersebut menempatkan kajian lintas budaya pada posisi strategis dalam pengajaran bahasa Arab pada abad 21, tidak terkecuali dalam konteks Indonesia.

Dalam pelaksanaan penelitian ini pengembangan buku ajar mata pelajaran bahasa arab dengan muatan materi deradikalisasi yang berbasis buku Ajar dan media sosial. Materi pelajaran dibuat berdasarkan literasi dalam kitab klasik dengan pertimbangan Peserta didik SMA dari segi usia berada pada masa remaja (15-19 tahun) yang merupakan masa peralihan antara masa kehidupan anak-anak dan masa kehidupan orang dewasa. Itulah sebabnya para peserta didik SMA pada masa ini banyak melakukan berbagai aktivitas untuk menemukan jati dirinya (ego identity). ( menurut Desmita: 2009 ) Perkembangan peserta didik SMA ditandai dengan sejumlah karakteristik penting berikut ini : (1) Memperoleh hubungan yang matang dengan teman sebaya, (2) Dapat menerima dan belajar peran sosial sebagai laki-laki atau perempuan dewasa yang dijunjung tinggi oleh masyarakat, (3) Menerima keadaan fisik dan mampu menggunakannya secara efektif, (4) Mencapai kemandirian emosional dari orang tua dan orang dewasa lainnya, (5) Memilih dan mempersiapkan karir di masa depannya sesuai dengan minat dan kemampuannya, (6) Mengembangkan sikap positif terhadap pernikahan, hidup berkeluarga, dan memiliki anak, (7) Mengembangkan keterampilan intelektual dan konsep-konsep yang diperlukan sebagai warga negara, (8) Mencapai perilaku yang bertanggung jawab secara sosial, (9) Memperoleh seperangkat nilai dan sistem etika sebagai pedoman dalam bertingkah laku, dan (10) Mengembangkan wawasan keagamaan dan meningkatkan pengalaman keberagamaannya. Dalam tahap ini ( menurut Novan Ardi Wiyani : 2013 ) disebut dengan kepercayaan sintetik konvensional. Pada tahapan ini peserta didik SMA patuh terhadap pendapat dan kepercayaan orang lain. Pada tahap ini peserta didik SMA cenderung ingin mempelajari sistem kepercayaannya dari orang lain di sekitarnya dan menerima sistem kepercayaan tersebut tanpa diikuti dengan sikap kritis dalam meyakininya.

Pelajaran dilaksanakan secara online melalui media social dan secara offline yang dilaksanakan didalam kelas. Penggunaan perangkat pengajaran, buku ajar dan media social, serta analisis kekurangan bahan ajar yang digunakan, nantinya akan dijadikan bahan kajian dalam penelitian pengembangan yang akan menghasilkan sebuah buku ajar adalah merupakan data yang akan dikumpulkan dalam penelitian ini. Dan siswa-siswi SMAN 1 Karangbinangun tahun pelajaran 2020/2021 merupakan subjek dari penelitian ini.

\section{Interkultural Dalam Pengajaran Bahasa Arab}

Pedagogi bahasa dengan orientasi kompetensi interkultural berfokus pada konstruks kesadaran tentang kealamiahan perbedaan budaya dengan cara membantu siswa mengidentifikasi 
persepsi mereka sendiri. Budaya siswa memberi kerangka kerja kognitif untuk memahami dunia di sekitar mereka6 Berikut aspek interkultural yang lazim menjadi pondasi awal dalam pengajaran bahasa Arab sebagai bahasa asing:

\section{Aspek Linguistik}

Secara ortografis, alfabet bahasa Arab terdiri dari 28 huruf, terdiri dari konsonan dan vokal, tidak mempunyai istilah huruf besar atau kecil, bentuk hurf beragam sesuai posisi dalam kata (awal, tengah, akhir), memiliki dua puluh tujuh konsonan, seperti huruf / و/ dianggap sebagai semivowel, tiga vokal pendek / a, i, u / dan tiga vokal panjang / $\bar{a}, \overline{1}, \bar{u} /$. Dalam konteks struktur bahasa, lazimnya kalimat dasar bahasa Arab menggunakan susunan VSO (Verb-SubjectObject). Kendati demikian, tidak sedikit dijumpai kalimat dasar bahasa Arab yang mendahulukan subject atas verb karena alasan gaya bahasa. Di samping itu, bahasa Arab juga identik dengan penggunaan pola morfologis7

\section{Diglosia}

Diglosia merupakan sebuah sikon bahasa yang di dalamnya terdapat klasifikasi kegunaan atas varian bahasa yang eksis pada masyarakat8 Dalam bahasa Arab, terminologi diglosia merujuk kepada variasi bahasa masyarakat Arab yang lazimnya dikenal dengan fusha dan 'ammiyah9

\section{Bahasa Tubuh (Body Language)}

Berikut beberapa bahasa tubuh yang telah menjadi konvensi masyarakat Arab:

1) Kontak mata: kontak mata adalah aspek yang paling menarik dari bahasa tubuh, dan memiliki banyak interpretasi dalam berbagai budaya. Bagi orang-orang Arab, mata adalah ekspresi kecantikan yang paling utama karena memberikan terlalu banyak rahasia dan kesan pada kesejahteraan individu. Dalam budaya Arab, memalingkan muka untuk waktu yang lama sering diartikan sebagai tanda tidak hormat atau menghindar, melihat ke bawah adalah tanda rasa malu atau tunduk, dan melihat ke atas dapat diartikan sebagai arogan atau merendahkan.10

2) Perenungan; orang Arab menyentuh dagunya dengan ibu jari untuk menunjukkan bahwa mereka memikirkan sesuatu atau seseorang. Bahasa tubuh ini menunjukkan kebijaksanaan dan kedewasaan mereka.

3) Memanggil; menggerakkan tangan dan jari terhadap diri sendiri dalam budaya Arab berarti 'datang ke sini'.

4) Tidak; mengangkat kepala ke atas dan mengklik lidah dalam budaya menunjukkan ketidak setujuan tentang sesuatu.

5) Terima kasih; dalam budaya Arab ekpresi terima kasih dengan bahasa tubuh dilakukan dengan cara menutup mata kemudian meletakkan tangan di dada.

6) Tidak menghormati saya; dalam budaya Arab bila seseorang menunjukkan kakinya saat duduk merupakan sebuah penghinaan, karena bagi mereka hal itu berarti 'kamu berada di bawah kaki saya.

\section{Kesantunan (Politeness Language)}

Samarah berpendapat bahwa kesantunan merupakan formulasi strategi dan tekhnik yang dioptimalkan oleh pembicara dengan motif yang beragam, seperti mempertahankan hubungan yang harmonis. Berikut poin-poin yang melingkupi kesantunan berbahasa dalam budaya masyarakat Arab:

1) Kesantunan masyarakat Arab disusun dan dikendalikan oleh dua pengaruh utama: iman agama, dan konvensi sosial. 
2) Kesantunan dalam bahasa Arab dapat dibagi kedalam 10 kategori semantik, yaitu: keramahan, syukur, kebajikan, rasa bersalah, mohon izin, penghargaan, kemurahan hati, rasa hormat, pengenalan percakapan, dan pengakuan status sosial.

3) Perilaku non verbal yang dianggap sebagai sebuah kesantunan dalam budaya masyarakat Arab misalnya: a) mencium pipi; b) membungkuk dan menurunkan pandangan untuk menyatakan rasa hormat bagi orang yang berposisi tinggi; c) berjabat tangan, diperkuat dengan penggunaan kedua tangan, diikuti dengan meletakkan tangan di hati.

4) Hal ini untuk mengekspresikan kesopanan, harmoni dan cinta

\section{Aspek Gender}

1) Berikut contoh aspek interkultural yang berkaitan dengan gender dalam masyarakat Arab: 1) laki-laki di depan wanita/istri ketika berjalan;

2) wanita harus menundukkan kepala dan mata tidak memandang lawan jenis ketika berkomunikasi; 3) seorang isteri memanggil suaminya sesuai dengan tempat dan kedudukan suami saat itu.

\section{Pengembangan Materi Pembelajaran}

Materi pembelajaran bahasa Arab pada jenjang SMA seyogyanya juga memasukkan unsur budaya bahasa. Dengan kata lain, pola komunikasi keseharian masyarakat Arab diposisikan sebagai unsur strategis di dalamnya, baik yang bersifat fusha pun ammiyah. materi pembelajaran bahasa Arab pada jenjang SMA terdiri dari dialog perkenalan, kehidupan keluarga, hobi, pekerjaan, remaja, kesehatan, fasilitas umum, pariwisata, kisah-kisah Islam, wawasan Islam, hari-hari besar Islam, dan tokoh-tokoh Islam. Adapun dalam penelitian materi dikembangkan dengan menambah kisah-kisah teladan (Naz'u al-Thathorruffil Islam) dan ayatayat al-Qur'an tentang jihad Dengan penambahan materi kaidah kata kerja dan 'adad / hitungan.

\section{KESIMPULAN}

Dari hasil penelitian yang dilakukan dapat diambil data bahwa erat kaitanya pendidikan bahasa arab dan usaha deradikalisasi agama. Hasil dari penelitian ini menunjukkan bahwa penerapan materi deradikalisasi mampu meningkatkan motivasi siswa dalam belajar bahasa Arab dan memahami Al-Qur'an. Kemudian, penambahan kosa kata bahasa arab sangatlah disarankan pada buku ajar Bahasa Arab untuk memberikan pencerahan bagi siswa tentang bahaya paham radikalisasi. Namun oleh karena usaha deradikalisasi tidak cukup dilakukan dengan satu metode dan pendekatan pada satu mata pelajaran maka selanjutnya penelitian akan usaha deradikalisasi ini akan dikembangkan pada mata pelajaran yang lain hususnya mata pelajaran agama.

\section{DAFTAR PUSTAKA}

Abdul Wahab, Laode. "Fenomena Diglosia Dalam Masyarakat Keturunan Arab Empang," AlIzzah 8, no. 2, 2013.

Acep Hermawan, metodologi pembelajaran bahasa Arab. (Bandung: Remaja Rosdakarya, 2011 ).

Agus. Sb Deradialisasi Nusantara, perang semesta berbasis kearifan local melawan radikalisasi dan terorisme, Jakarta: Daulat Press, 2016.

Ahmad, Zainal Arifin. Perencanaan Pembelajaran. Yogyakarta: Pedagogia 2012. 
Ahmad Asroni, Membendung Radikalisme, Merajut Kerukunan Umat Beragama: Sebuah Upaya Rekonstruktif terhadap Pengajaran Pendidikan Agama Islam di Perguruan Tinggi Umum ", Penamas, Vol. XXIV No. 1 Th. 2011.

Andi, Prastowo. Metode Penelitian Kualitatif. Yogyakarta: A-Ruzz Media 2011.

Al-huri, Ibrahim. "Arabic Language : Historic and Sociolinguistic Characteristics," English Literature and Language Review 1, no. 4, 2015.

Eldin. "Teaching Culture in the Classroom to Arabic Language Students", . hlm. 114.

Fisip, H. (2020, June). PROSIDING SLAMET RIYADI CONFERENCE ON PUBLIC ADMINISTRATION (SRIPA). In PROSIDING: SLAMET RIYADI CONFERENCE ON PUBLIC ADMINISTRATION (SRIPA) (Vol. 2, No. 1).

Astuti, Widi. "Diglosia Masyarakat Tutur Pada Penggunaan Bahasa Arab (Kajian Kebahasaan Terhadap Bahasa Fusha Dan Bahasa 'Amiyah Dilihat Dari Perspektif Sosiolinguistik),"

Jurnal Komunikasi Dan Pendidikan Islam 6, no. 2, 2017.

Ismail Hasani dan Bonar Tigor Naipospos, Radikalisme Agama di Jabodetabek \& Jawa Barat: Implikasinya terhadap Jaminan Kebebasan Beragama/Berkeyakinan Jakarta: Pustaka Masyarakat Setara, 2010.

Desmita, Psikologi Perkembangan Peserta Didik : Panduan bagi Orang Tua dan Guru dalam Memahami Psikologi Anak Usia SD, SMP, dan SMA, Bandung : Rosda, 2009.

Jan Franciszek Nosowicz and Joanna Szerszunowicz, "Preliminary Remarks on the Interdisciplinary Nature of Anthropolinguistics," Linguistics and Literature Studies 3, no. 6 (2015)

Kramsch, Claire, "Culture in Foreign Language Teaching," Iranian Journal of Language Teaching Research Urmia 1, no. 1, 2013. Al-Omari, Jehad. Understanding the Arab Culture (Oxford: Spring Hill House, 2008.

Mujib, Fathul. Rekonstruksi Pendidikan Bahasa Arab: Dari Pendekatan Konvensional Ke Integratif Humanis (Yogyakarta: Bintang Pustaka Abadi, 2010).

Nosowicz, Jan Franciszek and Joanna Szerszunowicz, "Preliminary Remarks on the Interdisciplinary Nature of Anthropolinguistics," Linguistics and Literature Studies 3, no. $6,2015$.

Samarah, Abdullah Yaqub. "Politeness in Arabic Culture," Theory and Practice in Language Studies 5, no. 10, 2015.

Sharaf Eldin, Ahmad Abdel Tawwab, "Teaching Culture in the Classroom to Arabic Language Students," International Education Studies 8, no. 2, 2015.

Susanti, I., Syairozi, M. I., \& Lukman, H. Y. W. (2021). Analisis Sistem Manajemen Dalam Pengelolaan Bumdes Di Desa Bluluk. Jurnal Sains Sosio Humaniora, 5(2), 701-710.

no. 2, 2017.

Watsono, Afdol Tharik. "Aspek Interkultural Dalam Pengajaran Bahasa Arab Sebagai Bahasa Asing Di Indonesia.” In Seminar Nasional Pengajaran Bahasa 2017, 1-14. Depok: Universitas Indonesia, 2017.

Wiyani, Novan Ardi. Pendidikan Islam Berbasis Anti terorisme di SMA, Jurnal: FTKIP Islam Bumiayu, Vol. 2, No.1, (Juni, 2013)

Wawancara: H.Ali Nurdin. Kepala SMAN 1 Karangbinangun.

Wawancara H.Anwar : Guru mapel PAI

Wawancara H.Ridlawan: Guru mapel B.Arab

Wawancara M.Exal Ainun Rafli: Siswa kelas XII IPA 3.

Zuly Qodir, Deradikalisasi Islam Dalam Perspektif Pendidikan Agama Jurnal Pendidikan Islam, Universitas Muhammadiyah Yogyakarta, Vo 1 No 2, 2013. 